\title{
SURVEY OF THE ATTITUDES OF BULGARIAN CONSUMERS TO WINE CONSUMPTION
}

\author{
Nikolay V. Logodashki ${ }^{1}$
}

Received: 10.10.2020, Accepted: 29.10 .2020

\begin{abstract}
Continuous research of consumer product choice is the basis for improving the characteristics of the offered product. This in turn leads to the creation of consumer satisfaction with the product, and it helps to increase the competitiveness of the products offered. The main goal of the present study is to investigate the consumer behavior and attitudes of Bulgarian consumers for wine consumption, as well as the impact of the COVID-19 pandemic on them. The main expected results are established attitudes towards wine consumption by Bulgarian consumers, which wine producers can use in making decisions related to competitiveness. The main research methods used in the study are content analysis, method of comparison, intuitive and systematic approach, method of analysis and synthesis, survey.
\end{abstract}

Keywords: consumer behavior, consumer attitude, wine, wine producers

JEL Codes: L66

\section{Introduction}

The study of consumer behavior and the factors that influence consumer choice are important for the success of wine producers and for increasing their competitiveness. When deciding what wine to produce and how to market it, the real needs of the customer are decisive. This is because the behavior of the customer as a purchaser, as well as as an evaluator of the product in the process of its consumption decisively motivates the marketing actions of the producer (Karakasheva L., L. Mencheva, etc., 1997). Consumer behavior is a subdivision of human behavior that is related to the decisions and actions of individuals in the purchase and use of products. (Goranova P. 2002) It is a process of selectivity of activity and the form of manifestation of the many personal elements of the consumer as interests, motive for behavior, consumer needs, etc. (Uzunova Yu.,

${ }^{1}$ Department of Management and Marketing, Faculty of Economics SWU "Neofit Rilski" Blagoevgrad, PhD student e-mail: nikolay.logodashki1985@gmail.com, ORCID ID: https://orcid.org/0000-0001-8674-8922; 
D. Doganov. 1992) Consumer behavior is an understanding of who buys and why consumers buy (or do not buy) products and services (Hawkins, D., R. Best, K. Coney. 1992), and the ability to anticipate consumer behavior is key to planning and managing in a dynamically changing environment. In this regard, Kotler connects the study of consumers by managers in order to explain who exactly buys, how exactly they buy, when they buy, where they buy and why they buy. (Kotler, Ph. 1993) To summarize, we can define consumer behavior as a system of purposeful and motivated actions of individuals undertaken in the search, purchase and use of products and services that meet certain needs.

\section{Discussion}

The companies operate in a highly competitive environment and it demands to synchronize the company's activities to market trends which appear as an essential prerequisite for acquiring competitive advantages. (Zlateva, D., Atanasova, A., Kalaidjieva, V., 2016) According to Filipova, the precise and reliable grouping of consumers in terms of their requirements and preferences gives the necessary information to managers to implement the right strategies to increase competitiveness. (Filipova M., 2004) In this regard, she points out that it is necessary to study the consumer choice of the product constantly, and on this basis to improve the characteristics of the proposed product continuously, which will lead to consumer satisfaction with the product, which in turn leads to increased competitiveness of the offered products. (Filipova, M. 2005)

Kalaydzhieva point out that the competitiveness must be seen as an organisational and managerial process that guarantees long-term success, taking into account resource efficiency and providing continuous self-control. By nature, competitiveness is relative rather than absolute. It is not a static, but rather a dynamic variable, since it is determined by existing competitors. According to her opinion every innovation provides an opportunity to increase the quality of the product or the activity, which in turn is one of the prerequisites for increasing competitiveness. Innovations in products related to newly emerging needs require satisfaction, and thus attract new customers, and expand the markets of the enterprise. (Kalaydzhieva, V. 2020).

Innovation is most often seen as a tool, as a factor for increasing the competitiveness or as an element of it. (Kalaydzhieva, V. (2019) Knowledge of the techniques and the product positioning, their parallel implementation in order to combine their advantages to achieve a synergy, enables companies to gain a strong competitive advantage that is relevant to establishing a permanent place 
on the market and development in a highly competitive environment. (Zlateva, D., Georgieva, Kr., 2015).

In order to study the attitudes of Bulgarian consumers to wine consumption, the author conducted a survey. 129 Bulgarian citizens took part in it. The study period is August-September 2020.

Figure 1. Gender of the survey participants

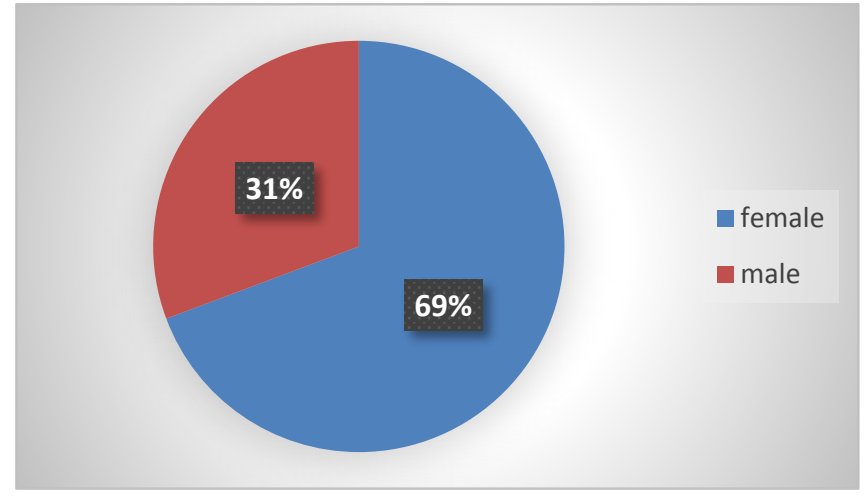

Source: personal survey

As can be seen from the results presented in Figure 1, 69\% of all respondents are women and $31 \%$ - men.

Figure 2. Age of the survey participants

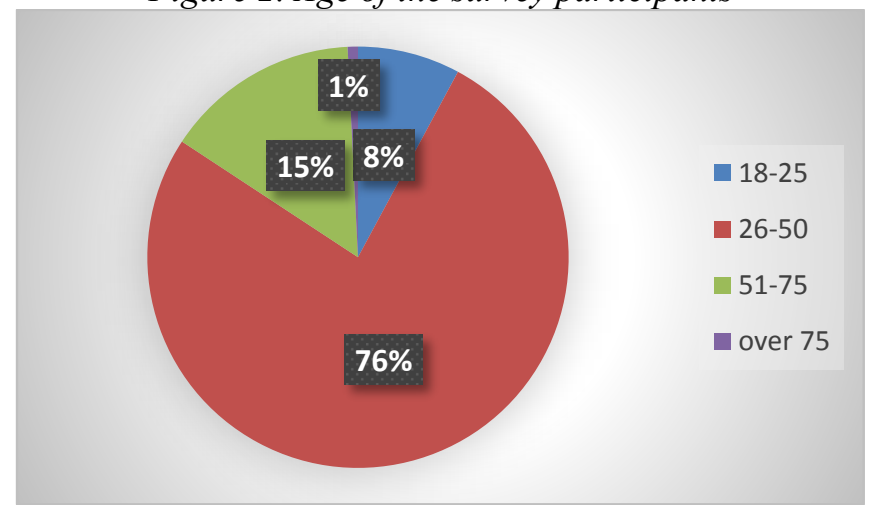

Source: personal survey 
From the obtained results illustrated in Fig. 2, regarding the age group of the respondents it is clear that $76 \%$ of them are aged between 26 and $50,15 \%$ are aged between 51 and $75,8 \%$ of them are between 18 and 25 , and $1 \%$ of them are over 75 years old.

Figure 3. Education of survey participants

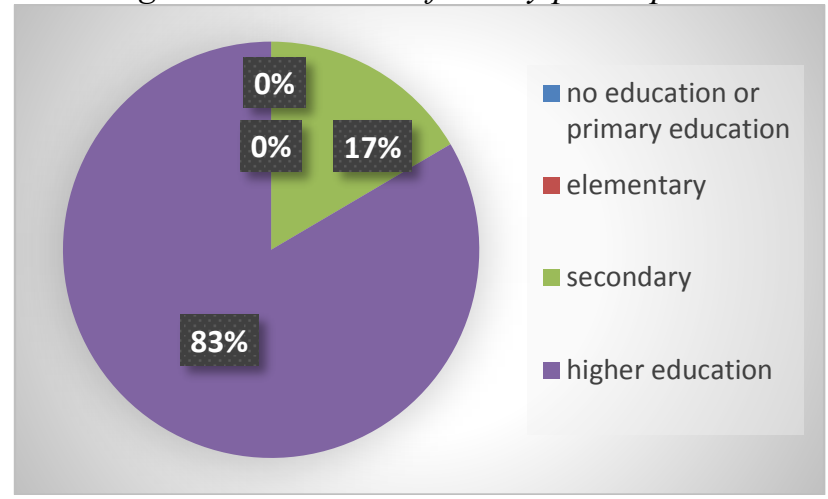

Source: personal survey

As can be seen from the results presented in Figure 3, the completed education of the participants in the study is as follows: $83 \%$ of the respondents have completed higher education, and $17 \%$ of them have completed secondary education.

Figure 4. Marital status of the survey participants

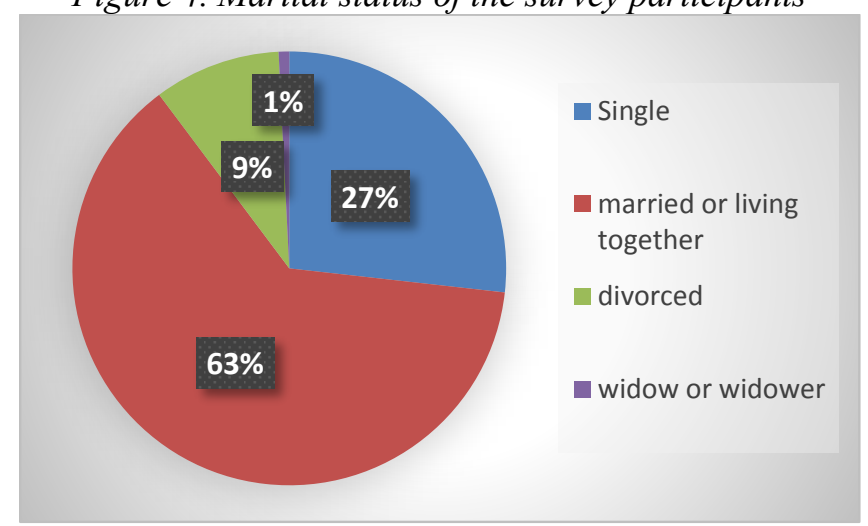

Source: personal survey 
From the results illustrated in Fig. 4 it can be seen that the largest number of respondents are married or people living with someone $-63 \%$, and $27 \%$ are single. $9 \%$ of the respondents are divorced and $1 \%$ of all are widows/ers.

Figure 5. Monthly income of the survey participants

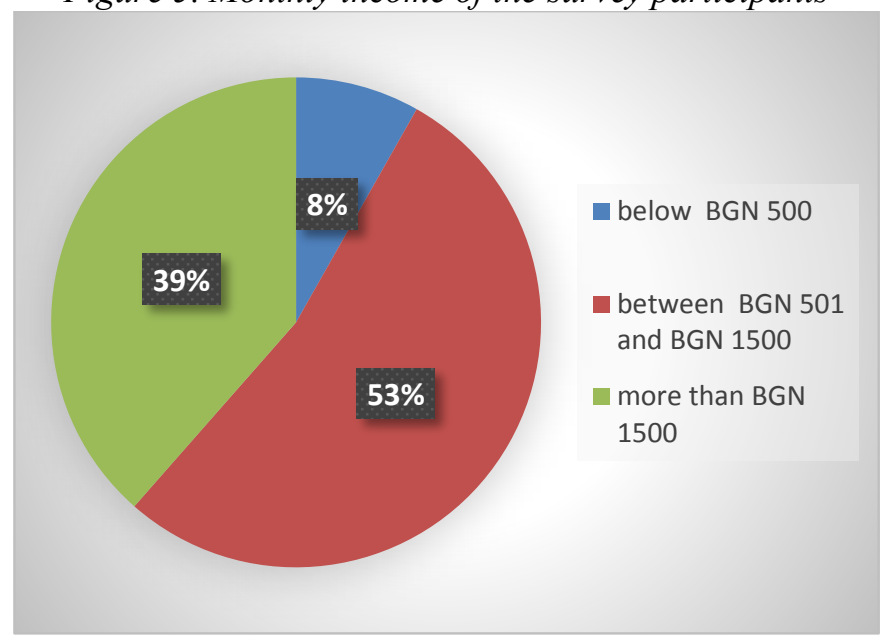

Source: personal survey

As can be seen from the results presented in Fig. 5, of those who classified their monthly income, the largest number of respondents earn between BGN 501 and BGN $1500-53 \%$. 39\% of them earn more than BGN 1,500 per month, and the least number are the respondents with a monthly income below BGN 500. $8 \%$. 
Figure 6. Preferences of Bulgarian consumers regarding wine consumption

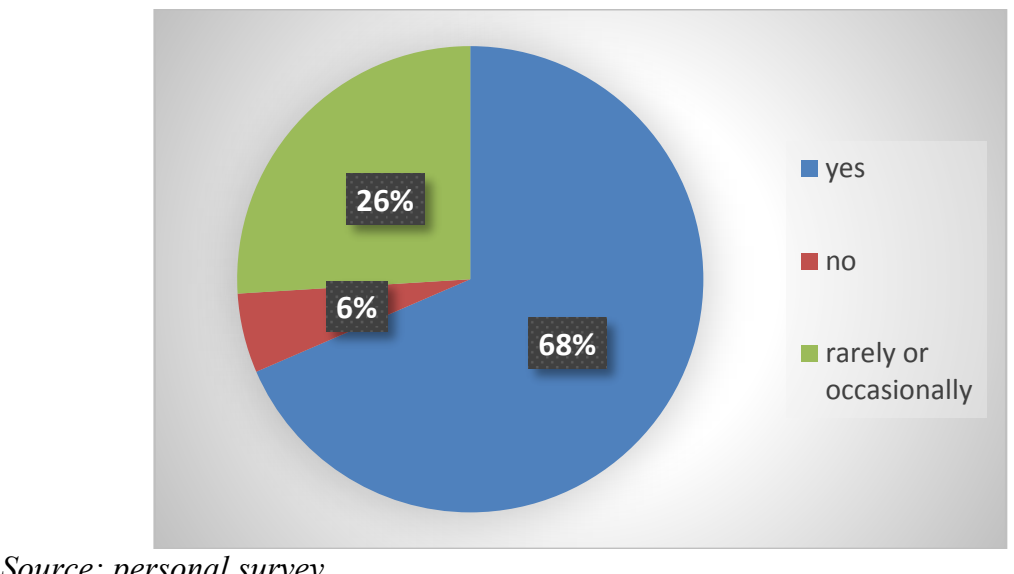

Source: personal survey

From the results shown in Fig. 6 , it is clear that $68 \%$ of the respondents indicated that they consume wine. $26 \%$ of them consume wine rarely, or occasionally, and only $6 \%$ of them do not consume wine. I.e. the largest number of respondents indicate that they consume wine, followed by those who consume wine infrequently or only occasionally, and the smallest number of participants in the study are those who do not consume wine.

Figure 7. Preferences of Bulgarian wine consumers to the main types of wine

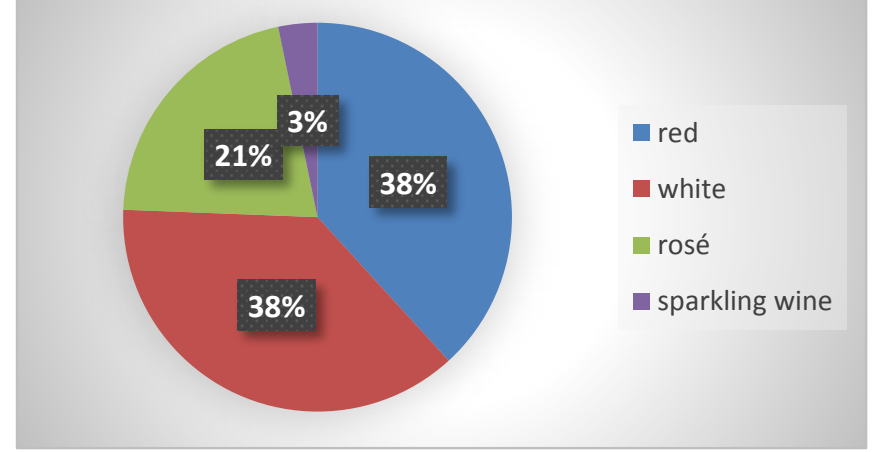

Source: personal survey 
From the results of the study presented in Fig.7 regarding the preference of the main type of wine, we can distinguish that the largest number of people prefer red wine $-39 \%$. People who drink white wine are one percent less - 38\%. $22 \%$ of respondents prefer to drink rosé, and $1 \%$ prefer sparkling wine. The results obtained by the author give us reason to say that there is almost no difference in consumer preferences between red and white wine, and rosé and sparkling wine are less preferred by Bulgarian consumers of wine.

Figure 8. Preference of Bulgarian wine consumers to sweet or dry type of wine

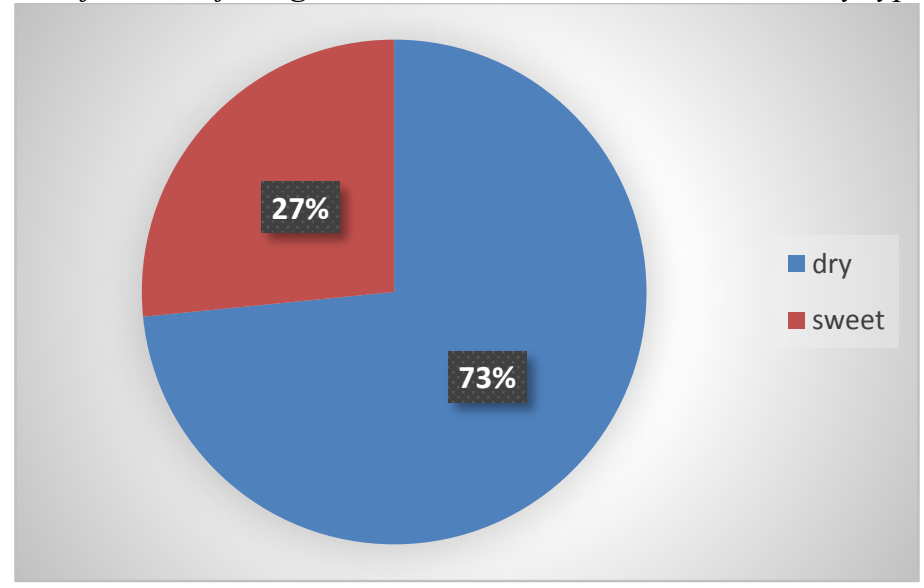

Source: personal survey

As can be seen from the results shown in Fig. 8, it is clear that $73 \%$ of the respondents prefer dry wine and $27 \%$ prefer sweet wine, which means that dry wine is preferred three times more often than sweet wine by the Bulgarian wine consumer. 
Figure 9. Preferences of Bulgarian wine consumers to its alcohol content

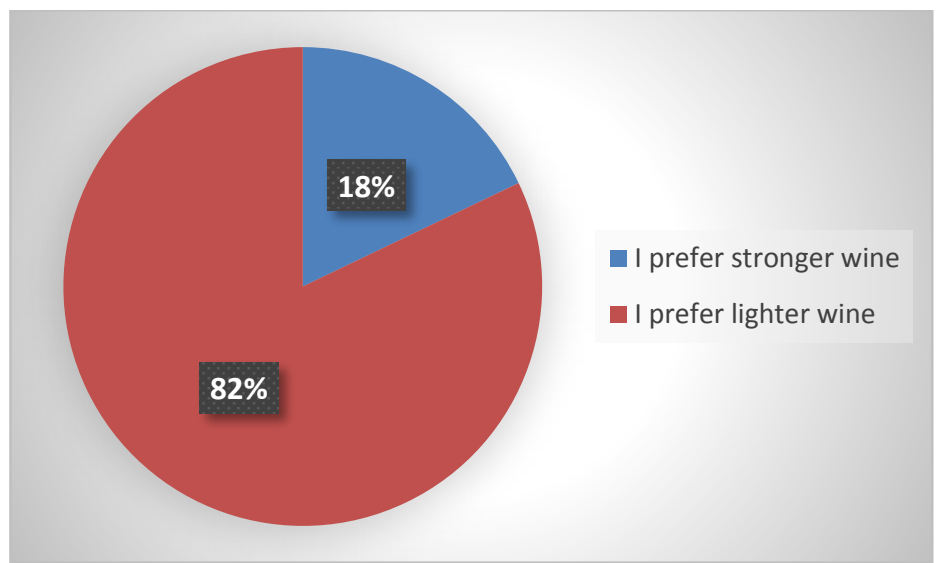

Source: personal survey

From the results illustrated in Fig. 9 it is clear that $82 \%$ are consumers who prefer lighter wine, compared to $18 \%$ who prefer stronger wine, ie. lighter wine is definitely much more preferable than the stronger one by the native wine consumer.

Figure 10. Preferences of Bulgarian wine consumers to Bulgarian or imported wine

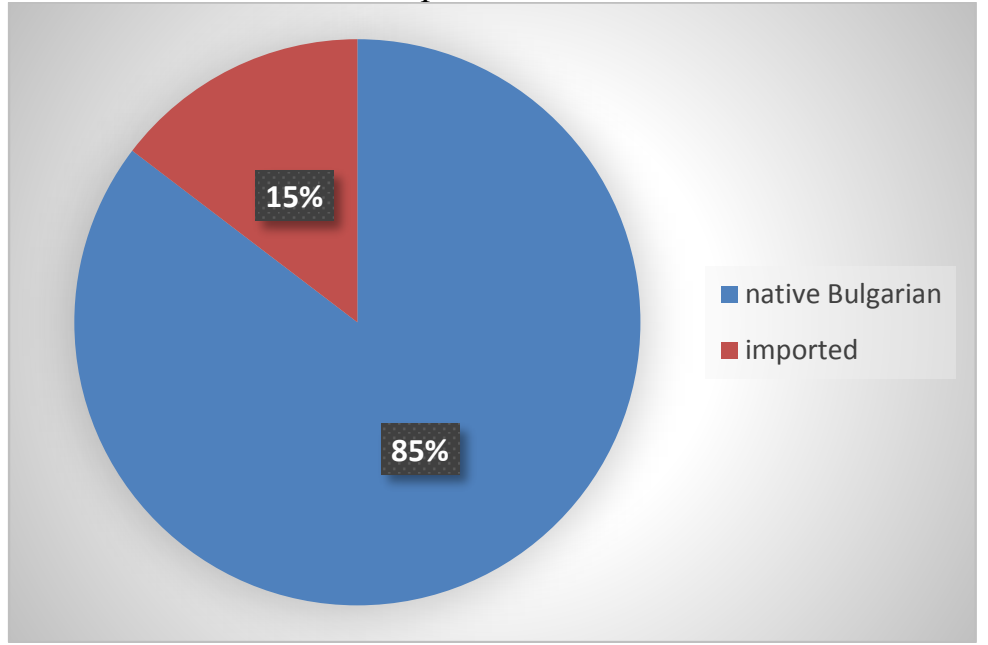

Source: personal survey 
Figure 10 shows the results obtained in a study of the preferences of Bulgarian consumers in the choice of wine - produced in Bulgaria or imported wine. As can be seen from Figure 10,83\% of the participants in the study prefer the native Bulgarian wine, and only $17 \%$ of them prefer imported wine. Given the answers thus obtained, we can conclude that Bulgarians mainly prefer to consume domestic wine production, and only a small part of them prefer to drink imported wine.

Figure 11. Preferences of Bulgarian wine consumers to wine from a certain region of Bulgaria

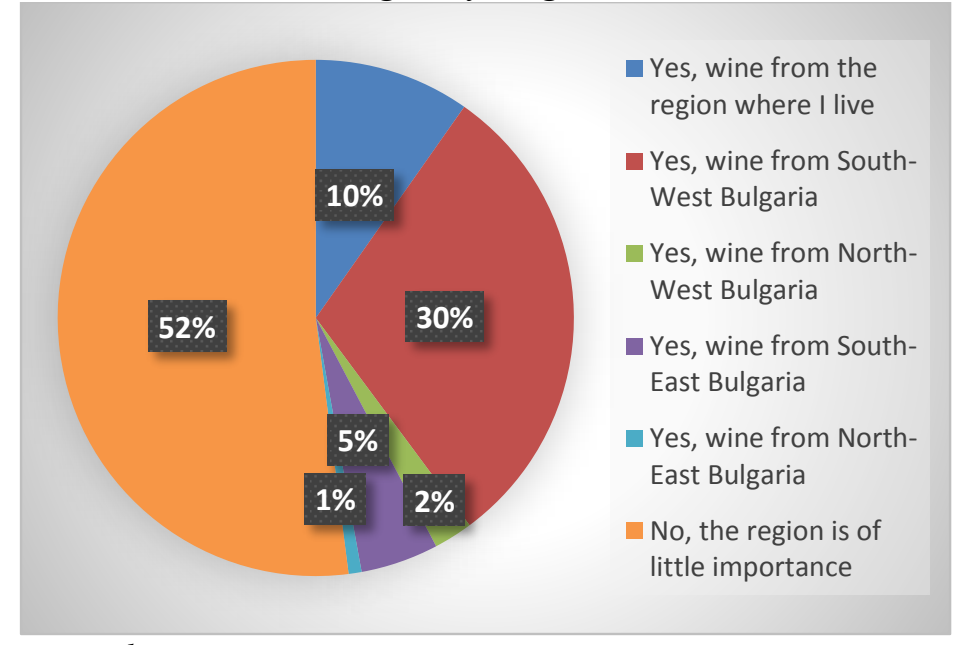

Source: personal survey

From the results shown in Fig. 11 it is clear that for 52\% of the participants in the study the region from which the wine they consume is produced is of little importance, and $30 \%$ choose wine produced in South-West Bulgaria. $10 \%$ of the consumers choose wine for consumption which is produced in the region they live in, $5 \%$ prefer wine produced in South-East Bulgaria, 2\% have indicated as their preference wine produced in North-West Bulgaria, and only $1 \%$ prefer wine produced in North-East Bulgaria. Based on the results of the survey we can point out that for more than half of the respondents the region from which the wine they consume is produced is of little or no importance, and the wine from the Southwestern region is the most preferred by respondents who prefer wine from a certain region in Bulgaria. One tenth of the respondents prefer to consume wine from their local cellars. The percentage of Bulgarian wine consumers preferring wine from North-East, South-East and North-West Bulgaria is very small. 
Figure 12. Preferences of Bulgarian consumers to the type of wine packaging

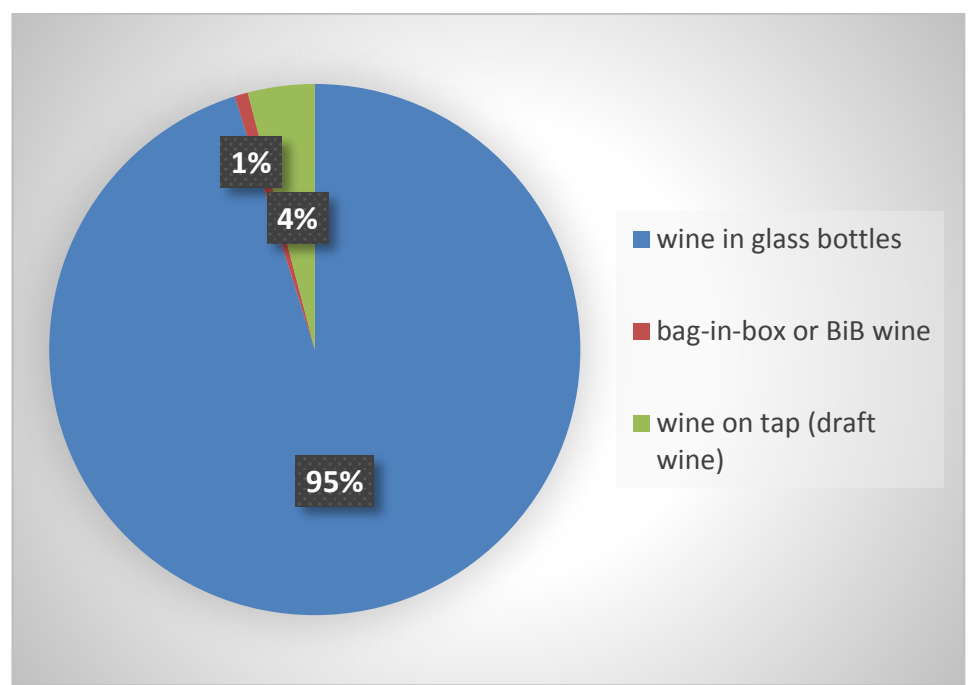

Source: personal survey

As can be seen from the results presented in Fig. 12 regarding the preferences of wine packaging, $95 \%$ indicated that the ideal wine for them is in a glass bottle, $4 \%$ prefer wine on tap, and $1 \%$ prefer bag-in-box wine, ie. almost all respondents prefer bottled wine. 
Figure 13. Preferences of Bulgarian consumers of wine to wine from a certain price range

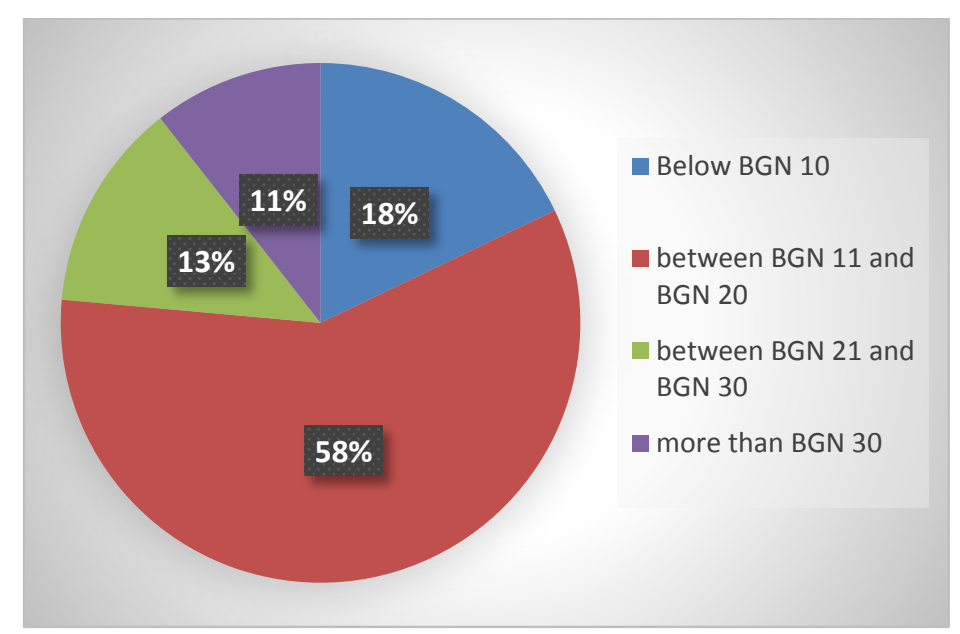

Source: personal survey

The results illustrated in Fig. 13 give us information about the price range of the wine consumed by Bulgarian consumers. $58 \%$ consume wine in the price range between BGN 11 and BGN 20, 18\% prefer wine below BGN 10, 13\% choose wine with a price between BGN 21 and BGN 30, and 11\% like wine over BGN 30. Given the results obtained in this way, we can come to the conclusion that the largest number of respondents drink wine at a price between BGN 11 and BGN 20, followed by those who drink wine at a price below BGN 10, and there are the least preferences for wine at a price between BGN 21 and BGN 30 and over BGN 30. 
Figure 14. Frequency of wine consumption by Bulgarian consumers

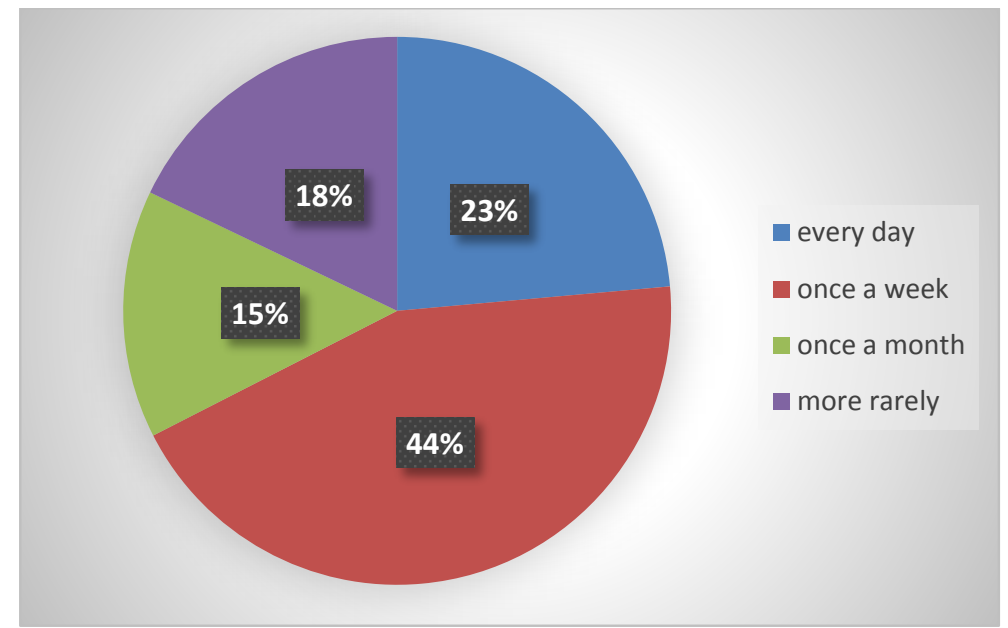

Source: personal survey

As can be seen from the results shown in Fig. 14, we can determine how often the surveyed consumers drink wine. $23 \%$ indicated that they drink wine on a daily basis, $44 \%$ once a week, $15 \%$ once a month, and $18 \%$ more rarely than that, from which we can conclude that in Bulgaria most wine is consumed once a week, followed by daily consumption, and wine is rarely consumed once a month and even more rarely. 
Figure 15. Influence of the COVID-19 pandemic on the change of the habits of the Bulgarian consumers of the consumption of wine

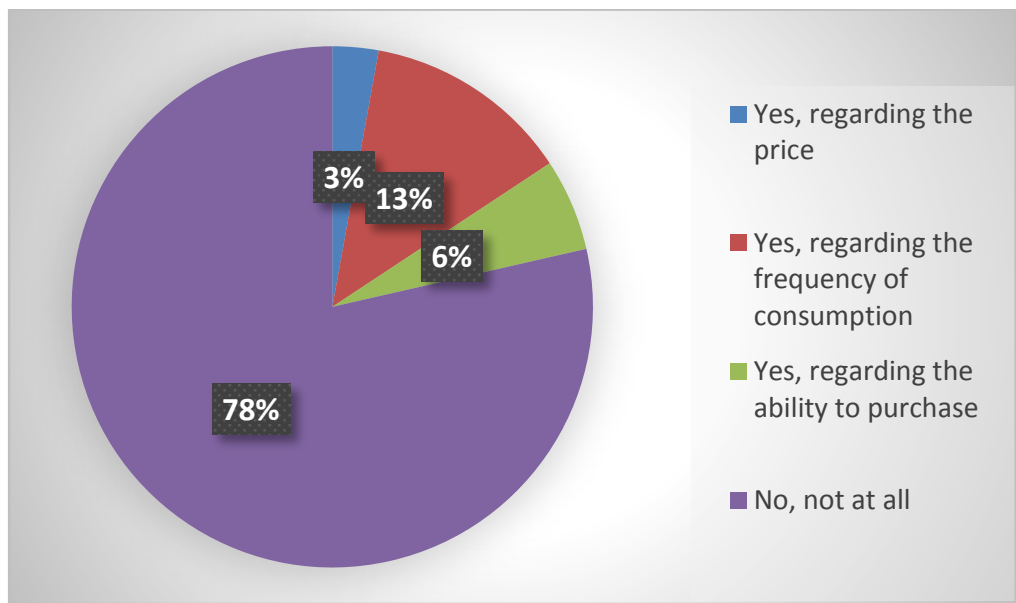

Source: personal survey

The results illustrated in Fig. 15 show that $79 \%$ of the participants in the study did not change their habits regarding wine consumption during the COVID19 pandemic, $13 \%$ indicated that their habits changed in terms of the frequency of wine consumption, $6 \%$ indicated an impact on their ability to purchase wine, and $3 \%$ were affected by the price. Based on the results of the study, we can summarize that more than three-quarters of the respondents were not affected in any way by the COVID-19 pandemic in terms of their consumption of wine, and the rest of them were affected accordingly in terms of frequency of consumption, purchase options,price.

As a favorite brand of Bulgarian wine, respondents indicated many and varied preferences, but some of the most popular Bulgarian wine brands are produced from the wineries Vini Boshkilov, Logodazh, Targovishte, Cherga, Bratya Minkovi, Damyanitsa, Todoroff, Mezek, Stambolovo, Black sea, Starosel, Katarzhina, 'Dve Mogili', Svishtov, Domaine Boyar, Midalidare, Make 98, Villa Justina, Medi vali, Zlaten Rozhen, Dalakov Kvevri, Yambol, Cycle, Ethno, Korten, Varna, Karnobat, etc. 


\section{Conclusion}

Based on the results obtained by the author's study of the attitudes of Bulgarian consumers to wine consumption, we can draw the following more significant conclusions:

First, $68 \%$ of Bulgarian consumers drink wine, $26 \%$ rarely, only occasionally, and $6 \%$ of them do not consume wine at all. The highest percentage of consumers drink red and white wine. Both types of wine occupy a relatively equal percentage as a preference, so it is difficult to determine which of the two types is more preferred by consumers. Expectedly, rosè is the next type preferred by the Bulgarian consumers of wine, and proof of the low popularity on the one hand, and perhaps culture, on the other hand, is the small percentage of consumers of sparkling wine in our country. Bulgarian consumers definitely prefer twice more dry wine than sweet wine. They also prefer to consume almost four times more light wines than stronger ones.

Second, over $80 \%$ of Bulgarian wine consumers prefer native Bulgarian wine, and less than $20 \%$ of them prefer imported wine. Despite the great competition on the wine market in our country, a large part of Bulgarians are prefer the native wine, compared to renowned brands of imported wines. Over $50 \%$ of Bulgarian consumers do not consider as essential the region in which their preferred wine is produced. $30 \%$ of Bulgarian consumers drink wine produced in South-West Bulgaria, which indicates that this region produces wine valued by the Bulgarian wine consumer. $10 \%$ prefer wine produced from local wineries in the regions where they live, and less than $10 \%$ choose wine produced in other parts of Bulgaria. Almost all Bulgarian consumers (95\%) prefer bottled wine, and a small part of them choose draft wine (4\%) and bag-in-box wine (1\%).

Third, Bulgarian consumers of wine consume the most wine in the price range between BGN 11 and BGN 20 (58\%), followed by the consumer who consumes wine below BGN $10(18 \%)$. The third place take consumers whose preferences are for wine with a price between BGN 21 and BGN 30 (13\%), and the least Bulgarians consume wine over BGN $30(11 \%)$. The largest percentage of Bulgarian consumers drink wine once a week (44\%), followed by consumers who drink wine on a daily basis (23\%). The third place take consumers who drink wine more rarely than once a month (18\%), and the last place take Bulgarian consumers who tend to consume wine once a month (15\%). $78 \%$ of Bulgarian consumers were not affected in any way by the COVID-19 pandemic in their habits regarding the consumption of wine, and a small part of them (13\%) were affected only in terms of frequency of consumption. $6 \%$ of the consumers were affected by the COVID-19 pandemic in that it prevented them financially from 
buying wine, thus affecting their normal wine consumption, and 3\% compromised on wine that was cheaper and more affordable for them than usual, thus they were affected by the pandemic, too.

Fourth, some of the most preferred Bulgarian wine brands, which are preferred by Bulgarian consumers are produced from the wineries Vini Boshkilov, Logodazh, Targovishte, Cherga, Minkovi Brothers, Damyanitsa, Mezek, Stambolovo, Starosel, Katarzhina, Dve Mogili, Svishtov, Domain Boyar, Midalidare, Make 98, Villa Justina, Medi vali, Zlaten Rozhen, Dalakov Kvevri, Yambol, Ethno, Korten, Varna, Karnobat, Todoroff, Black sea, Cycle, etc.

\section{REFERENCES}

Filipova M. (2004) Improvement of Competitive Power of the Brewery Company, Sofia

Filipova, M. (2005) Managing of the Competitiveness in Brewery industry, In 10-th National Symposium Quality, Competitiveness, Sustainable Development", UNWE Press, Sofia

Goranova, P. (2002) Theory of consumer behavior, Svishtov

Hawkins, D., R. Best, K. Coney (1992) Consumer Behavior, IRWIN, INS 1992

Kalaydzhieva, V. (2019) Model for Exploring the Influence of Innovations on the Competitiveness of Enterprises, Enhancing Competitiveness of National Economies and Enterprises, Nis

Kalaydzhieva, V. (2020) Innovation, Competitiveness and Internationalization of the Business in Bulgaria, Management - Tourism - Culture, Ignatianum University Press, Krakow

Karakasheva, L., L. Mencheva et al (1997) Marketing, S., 1997

Kotler, Ph. (1993) Fundamentals of Marketing, Volume I, S., 1993

Uzunova, Yu., D. Doganov (1992) et al., Marketing for all, Sofia, 1992

Zlateva, D., Atanasova, A., Kalaidjieva, V. (2016) Entrepreneurship, innovation and online marketing as factors to increase the companies' competitiveness, Sixth International scientific conference: The possible, the real and the virtual in the modern world: proceedings, 2016 ISBN 978-608-4574-750 http://www.eurm.edu.mk/novosti/sestakonf/zborniktrudovi16elek.pdf)8

Zlateva, D., Georgieva, Kr. (2015) Strategies For Successful Online Product Positioning. Building Trust In Online Discourse, Macedonian International Journal of Marketing, ISSN 1857-9787, http://bit.ly/349YL6X 